2. Caan W. Remember the links in the causal chain of fetal alcohol effects. Lancet 2007; 369(9575): 1789.

3. Luty J. Specialised alcohol treatment services are a luxury the NHS cannot afford. Br J Psychiatry 2008; 192: 245-247.

4. Baldacchino A, Caan W, Munn-Giddings C. Mutual aid groups in psychiatry and substance misuse. Ment Health Subst Use 2008; 1: 104-117.

DOI: 10.3399/bjgp08X302727

\section{Plain English}

Andrew Bolton, a very successful fund manager, advises that whenever you plan to buy a stock, try to explain the reason for your choice in a few simple sentences that your teenage children can understand.

I have recently applied this stratagem to the 'conclusion' section of BJGP original article summaries. Complete confusion ensues; the sentences are long and obfuscatory and the point/benefit of the research baffling to my children and myself.

Please try to use simple clearer English. If a research team cannot really explain simply what they are trying to do and why, ask for a revised draft. Does the College now have a in-house style that few ordinary jobbing GPs can understand?

NB enjoyed the Pickles Lecture ${ }^{1}$ and the 'proper doctor' vignette. ${ }^{2}$

\section{Roderick Champ}

Urishay Barn, Michaelchurch Escley,

Hereford, HR2 OLR.

E-mail: quinnchamp@gmail.com

\section{REFERENCES}

1. Hilton S. Education and the changing face of medical professionalism: from priest to mountain guide? Br J Gen Pract 2008; 58(550): 353-361.

2. Lester H. On being a proper doctor. Br J Gen Pract 2008; 58(550): 378 .

DOI: 10.3399/bjgp08X302736

\section{Re: Plain English}

A familiar (and fair) point. The bit that we think should be easy to grasp is the
'How this fits in' section - that at least is the intention. The instruction to write it so an intelligent child can understand it is so useful we'll add it - Ed.

DOI: 10.3399/bjgp08X302745

\section{HIV testing}

We wholeheartedly agree with the letter from Barber et al ${ }^{1}$ regarding the need for a lower threshold of HIV testing outside of traditional GU medicine settings.

Clinicians in general practice should not be afraid of offering HIV tests where clinically indicated or if requested by the patient. Let's reiterate the advice that 'counselling' is not required (although you must gain consent from the patient before testing) and that life insurance issues should not be a deterrent to offering an HIV test. If the HIV result returns as negative, insurance companies do not need to be informed; in fact, with improved treatments resulting in a better prognosis, some insurance companies are now happy to offer cover to some HIV-positive patients.

What are the clinical indications for HIV testing? Not only the signs and symptoms that would raise suspicion of HIV infection, but also the opportunistic offer of an HIV test to those patients from certain high-risk groups, such as:

- people from sub-Saharan Africa (and their sexual partners);

- men who have sex with other men (and their sexual partners);

- injecting drug users (and their sexual partners); and

- commercial sex workers and their clients.

What signs and symptoms might prompt suspicions of HIV infection?

- tuberculosis (the British HIV Association recommends all patients with TB, regardless of their perceived risk of HIV infection, should be offered an HIV test ${ }^{2}$ );
- non-Hodgkin's lymphoma;

- recurrent skin infections (shingles, tinea, folliculitis); and

- severe or recalcitrant seborrhoeic dermatitis.

This list is not exhaustive and further, more comprehensive advice on HIV in primary care is available in an easy-toread booklet produced by the Medical Foundation for AIDS and Sexual Health (MedFASH) and available to download for free from their website. ${ }^{3}$

Guidance on managing other sexually transmitted infections in primary care has been produced by the Royal College of General Practitioners (RCGP) with the involvement of the British Association for Sexual Health and HIV $(\mathrm{BASHH})^{4}$, and is also available to download for free from the RCGP and BASHH websites.

The RCGP, supported by the Department of Health in partnership with BASHH, the Faculty of Sexual Health and Reproductive Healthcare, the Royal College of Nursing, and other relevant stakeholders, is also producing an Introductory Certificate in Sexual Health aimed at increasing awareness of HIV and sexual health matters in general practice. Using a similar format to the highly successful RCGP Certificate in the Management of Drug Misuse Part 1, it will consist of an e-module and a face-to-face training day. This course is specifically aimed at generalists in general practice and addresses sexual health care including taking sexual histories, contraceptive issues, and management of STIs including HIV. (Further details can be obtained by emailing Russell Fleet at MedFASH. Contact details can be found at www.medfash.org.uk/)

Rates of HIV continue to rise in the UK. General practice clinicians are ideally placed to be vigilant with regard to HIV testing and this was highlighted last year by a letter from the Chief Medical and Nursing Officers encouraging HIV testing in all healthcare settings outside of those traditionally offering the service. ${ }^{5}$ Ample guidance is being made available to assist clinicians 
with the confidence to do so.

\section{Neil Lazaro}

Department of GU Medicine,

Royal Preston Hospital, Preston, PR2 9HT.

E-mail: nlazaro@doctors.org.uk

\section{Ruth Lowbury}

Medical Foundation for AIDS \& Sexual

Health (MedFASH), London

\section{Ewen Stewart}

Rose Garden Medical Centre, Leith, Edinburgh

\section{Chris Ford}

Lonsdale Medical Centre, London

\section{Gill Tonge}

Peterloo Medical Centre, Middleton, Manchester

\section{Kate Pearson}

Department of GUM, St John's Hospital, Chelmsford, Essex

\section{REFERENCES}

1. Barber TJ, Menon-Johansson A, Barton S. How can we remove barriers to HIV testing outside of a GUM setting? Br J Gen Pract 2008; 58(550): 365.

2. Pozniac AL, Miller RF, Lipman MCI, et al. British HIV Association treatment guidelines for TB/HIV infection. Feb 2005.

http://www.bhiva.org/files/file1001576.doc (accessed 9 May 2008).

3. Madge S, Matthews P, Singh S, Theobald N. HIV in Primary Care (published 2004, revised 2005). http://www.medfash.org.uk/publications/documen ts/HIV_in_Primary_Care.pdf (accessed 9 May 2008).

4. Lazaro N. Sexually transmitted infections in primary care. 2006.

http://www.rcgp.org.uk/PDF/clinspec_STI_in_pri mary_care_NLazaro.pdf (accessed 9 May 2008).

5. Donaldson L. Improving the detection and diagnosis of HIV in non-HIV specialties including Primary Care. Department of Health 2007 http://www.info.doh.gov.uk/doh/embroadcast.nsf/0 /EE0FA479BAA64A1B80257355003DFB47/\$File/Im proving $\% 20$ the $\% 20$ detection $\% 20 \& \% 20$ diagnosis $\%$ 20of\%20HIV\%2013\%2009\%2007.rtf?OpenElement (accessed 9 May 2008)

DOI: 10.3399/bjgp08X302754

\section{History of GP obstetrics}

I was delighted to read David Jewell's March focus column in the BJGP, which has stimulated this communication.
I was a GP obstetrician from January 1947 to 1981 . There has been increasing pressure from mothers, midwives, and health visitors to return to the days of high percentage home delivery where suitable. We are all aware of its advantages but they are much unsung.

In the period prior to the NHS in 1948, midwives were based in clinics run by the $\mathrm{MOH}$ (Medical Officer of Health) in conjunction with the MOH's assistants; they gave antenatal care and delivered babies at home. Should an emergency arise, the midwife would send for a doctor; one may or may not be readily available at that time, in which case time would be wasted by having to 'ring round' for help.

It was a time, early in my career, that 'fate' intervened and I answered such a call. On arriving I found the Superintendent of District Midwives (Miss D) and a trainee midwife had delivered the baby, but this was followed by severe post-partum haemorrhage. There was much loss of blood and an unconscious mother. I raised the foot of the bed by 18 inches, washed my hands quickly, and extracted the placenta with one hand, collected the lax uterus between both, gave ergometrine IV, and rigged a glucose saline drip followed by preconstituted plasma (all of which I carried in my care).

While the drip ran I made a quick visit to the path lab where my helpful friends provided three bottles of suitably matched blood. Returning to the scene I ran this in and awaited events.

It did not take long for the mother to awake, take baby to the breast, and recover before secondary shock could supervene. Further nursing help arrived so, having 'squared off' the bedroom and recovered ourselves, Miss D and I sought relaxation in a local coffee house.

We both agreed that this sort of situation must not happen again. We met two or three times afterwards with ideas to present to the $\mathrm{MOH}$ and GPs. This 'incident' was the initiating factor to change. It did not take long for my
GP colleagues to realise the need for an organised pattern of care throughout pregnancy, delivery, and post-pastum period.

The local medical committee formed an obstetric sub committee composed of a consultant obstetrician, a pathologist, three GPs, a paediatrician, and the $\mathrm{MOH}$. Their recommendations emerged as follows:

- All mothers-to-be should 'book' their GPs and midwives in early pregnancy;

- They would examine the mother on alternate occasions throughout the pregnancy, monthly until the 28th week, fortnightly until the 36th, then weekly until delivery;

- Mothers would carry a maternity record card which would be filled in at each visit; and

- When labour commenced, the midwife would be informed and attend, the GP contacted so that he would attend.

In the 20 years or so when the local statistics were available, an average of $50 \% \mathrm{GP} / \mathrm{midwife}$ deliveries occurred at home, $25 \%$ by GPs in the local authority maternity home, and $25 \%$ by specialists in hospital. Perinatal mortality as reported by the $\mathrm{MOH}$ for the period showed that Ipswich statistics were equal to the lowest in the world.

I venture the thought that good organisation saves more lives than brilliance. It can be done; it should be done. We GPs owe it the families in our care.

\section{Roy Webb}

Green Gables, Kersey, Suffolk IP7 6EB.

\section{REFERENCE}

1. Jewell D. March focus. Br J Gen Pract 2008; 58(548): 146

DOI: 10.3399/bjgp08X302763

\section{Home deliveries}

I am aged 83 and was a GP for 34 years from 1954. I was on the GP obstetric list 